of malaria control which the Shell Company produced in 1940. The publishers of the present volume also acknowledge that the Shell International Chemical Company made its publication possible. It is perhaps natural that with this sponsorship the emphasis should be almost entirely on the chemical methods of control.

The information about the insects themselves is very scanty. There is a short but admirable chapter on the development in one species or another of resistance to most of the insecticides. This is now such a menacing development that there is a strong case for devoting more attention to the ecology of the insect vectors and reconsidering the possibilities of some of the older methods of control. It might have been difficult to do this in such a short, concise volume, and what they set out to do the authors have done very successfully.

O. W. RICHARDS

\section{FLESH FOOD AVOIDANCES IN THE OLD WORLD}

\section{Eat Not this Flesh}

Food Avoidances in the old World. By Prof. Frederick J. Simoons. Pp. xiii + 241. (Madison, Wisc. : University of Wisconsin Press, 1961.) 6 dollars.

T HIS book is the work of a cultural geographer. While travelling across Africa from Ethiopia to Nigeria some years ago, the author noted that there were large areas where a particular flesh food was used and others where the same food was avoided with strong feolings. Following up the interest thus aroused, he examined the cultural and religious prejudices involved in the use of pork, beef and the flesh of horses, camels and dogs. (Curiously, the use of neither goat flesh nor mutton is discussed.) The author exposes the inadequacy of a common assumption that food avoidances are based on rational considerations - he rejects, for example, the thesis that the ancient Jews abstained from pork on hygienic grounds. $\mathrm{He}$ points out how in some instances, as abstention by Europeans from the flesh of dogs and cats, there is incompatibility between associating with these animals as domestic pets and treatment of them as a source of food. He lays great stress on the significance of religious belief as an element in food avoidance, and points to the way in which the prophet or other founder of a religion may play a critical part in promoting this. He also indicates how some food avoidances are correlated with the desire of a social group to improve its status relative to othersa process seen in modern India as some caste groups tend to follow the Brahmanical custom of not eating meat.

The general treatment of the book is itemistic, with instances given from a very wide geographical range, without much indication of the social and economic context in which the use or avoidance of the food occurs. Five maps showing the distribution of certain flesh foods are informative, but other maps showing the location of social groups are much less so. About half the book is taken up with maps, notes, bibliography and index.

The study is useful as a general source of information, and stimulates thought about economic and social effects of the great variation in choice of flesh food. The author is loss successful in advancing reasons for these food avoidances than he is in describ- ing them. For example, his hypothesis that prejudice against the pig and pork arose as the reaction of Asian pastoralists against an animal alien to their way of life and was then diffused to the sedentary peoples with whom they had contact is not very convincing. But for this he can scarcely be criticized, because of the general lack of historical information about the origins of such customs.

What the book does bring out is the need for more specific analytical studies of food usages directly related in a systematic way to economic, social and ritual considerations in particular communities.

Raymond Firth

\section{DICTIONARY FOR TEXTILE COLOUR CHEMISTS AND PRINTERS}

\section{Dictionary of Dyeing and Textile Printing}

By H. Blackshaw and R. Brightman. Pp. iv +221 . (London: George Newnes and Co., Ltd., 1961.) $30 s$. net.

THE authors of this little dictionary have spent

many years in dyeing and textile printing and so are well qualified for their task. They provide nearly 1,500 definitions relating to dyeing, printing and finishing processes and machines, as well as to the chemicals and auxiliary products used. Other subjects covered are textile fibres, colour terminology, chromophoric systems, natural colouring matters, and fastness testing.

Rather more than 100 of the definitions given are those produced-after much debate-by the Terms and Definitions Committee of the Society of Dyers and Colourists, and these definitions are acknow. ledged and indicated in the text. Apart from items concerning the Society of Dyers and Colourists, the present dictionary does not overlap to any great extent with the Textile Institute's publication, Textile Terms and Definitions, from which the authors have borrowed in a few cases. Sometimes they have preferred to give a fuller definition rather than the very concise official version. It is easy to think of a few more terms that they might have defined, but difficult to think of many.

The authors are very reliable when dealing with their own field, but outside this field they frequently go astray. For example, distillation is confused with fractional distillation, and chelation with intramolecular hydrogen bonding. Proof reading has been adequate, except with empirical and structural formulæ and with equations. It is to be hoped that consultation and careful checking will precede publication of the second edition.

The text is illustrated with thirteen useful diagrams of machines-with the exception of the final one (Fig. 13), which is an unlucky choice. There is, in addition, a "reading list", as well as a useful appendix consisting of an alphabetical index of the more important man-made fibres, although such lists become out of date very quickly.

In view of the slow progress invariably made by committees concerned with terminology, the authors are to be congratulated on their enterprise. Their little dictionary is likely to become popular among those concerned with dyeing and textile printing, very few of whom can be familiar with all the terms defined.
C. L. BIRD 